\title{
KONSEP TRI ANGGA DALAM BELAJAR TEKNIK TARI BALI
}

\author{
Oleh: \\ Ida Ayu Gede Prayitna Dewi \\ dayuprayitnaunhidps@gmail.com \\ UNHI Denpasar \\ I Kadek Satria \\ satcitah@yahoo.com \\ UNHI Denpasar
}

\begin{abstract}
ABSTRAK
Salah satu konsep keagamaan Hindu yang relevan dengan Teknik Tari Bali adalah konsep Tri Angga, dimana konsep ini merupakan konsep yang ada dalam pembagian tubuh manusia dengan istilah utama angga, madya angga, dan nista angga. Ketika konsep ini masuk di dalam Teknik Tari Bali, maka dapat dipahami bahwa konsep ini mampu memberikan pemahaman yang lebih terhadap pembagian tubuh saat mempelajari perbendaharaan gerak yang ada dalam teknik tari Bali. Pembagian tubuh ini mampu memudahkan pembelajaran dengan mengklasifikasikan gerak-gerak sesuai dengan pembagian tubuh (angga) penari. Utamaning angga merupakan bagian utama dalam tubuh yang dalam estetika Hindu dikaitkan dengan bagian yang paling disucikan adalah bagian kepala. Madyaning Angga merupakan bagian kedua dalam pembagian tubuh di antaranya bagian torso atau badan, dari bahu hingga pinggul. Dalam bagian ini terdapat banyak perbendaharaan gerak yang ada, beberapa contohnya adalah gerakan ngejat pala, ngeseh, ngelo, nyeleog, dan lainnya. Nistaning angga adalah bagian terakhir dari pembagian ini yang terdapat pada bagian bawah pinggul dan kaki.
\end{abstract}

Kata Kunci: tari Bali, tri angga, Hindu, estetika

\section{ABSTRACT}

One of the Hindu religious concepts that are relevant to the Balinese Dance Technique is the Tri Angga concept, where this concept is a concept that exists in the division of the human body with the main terms angga, madya angga, and nista angga. When this concept is included in the Balinese Dance Technique, it can be understood that this concept is able to provide a greater understanding of the division of the body when studying the vocabulary of motion that exists in Balinese dance techniques. This division of the body is able to facilitate learning by classifying movements according to the division of the body (angga) dancer. Utamaning angga is the main part in the body which in Hindu aesthetics is associated with the most purified part is the head part. Madyaning Angga is the second part in the division of the body including the torso or body, from shoulders to hips. In this section there are many treasures of motion that exist, some examples are the movement of the nutmeg, ngeseh, ngelo, ngeleog, and others. Nistaning angga is the last part of this division found in the lower part of the hips and legs.

Keywords: Balinese dance, tri angga, Hinduism, aesthetics 


\section{PENDAHULUAN}

Perbincangan dan pengkajian mengenai Budaya masih tetap menjadi hal yang menarik apalagi dalam kondisi perkembangan jaman yang kian mengarah pada modernisasi. Modernisasi yang terjadi tentunya memiliki dua sisi efek yang berbeda, baik sisi efek kelebihan maupun kekurangan yang berdampak langsung pada karakteristik masyarakatnya. Kenyataan yang terjadi dalam masyarakat dewasa ini adalah semakin banyak budaya yang menyimpang bahkan terhapus dan tidak berada dalam kaedah yang sebenarnya. Hal ini terjadi tentu saja karena adanya pengaruh budaya luar Bali yang membaur dalam kehidupan orang- orang Bali Kini, sehingga pemikiran yang global dan universal selaras dengan kehidupan kekinian masyarakat Bali. Budaya yang kini berkembang dalam kehidupan masyarakat Bali masih dapat dipertahankan oleh masyarakat Bali sendiri tanpa menutup diri namun menerimanya secara terbuka dengan tetap menjadikan Budaya asli sebagai kebanggaan tersendiri. Keunikan Budaya Bali dapat tergambar jelas dalam hal kesenian yang telah tersohor di dunia sejak jaman dahulu. Kini masyarakat Bali bertugas untuk mempertahankannya dengan baik dan tetap memiliki rasa tanggung jawab terhadap Budaya dan kesenian tersebut.

Budaya Bali memiliki berbagai bentuk, dan telah mempengaruhi pola dan tata kehidupan masyarakat Bali masa kini. Budaya dan tradisi masih terjaga dengan baik sejalan dengan perkembangan ilmu dan teknologi serta gaya hidup masyarakat jaman sekarang. Budaya memiliki salah satu unsur penting di dalamnya, yaitu kesenian. Tentu saja kata kesenian di Bali adalah sebuah ikatan yang kuat terhadap pandangan dan karakteristik orang Bali yang memiliki identitas tersendiri, membedakannya dari masyarakat luar Bali. Kesenian sudah mendarah daging dalam kehidupan orang Bali baik yang tercermin dari kehidupan sosial maupun kehidupan beragama dan keyakinan. Salah satu bentuk kesenian yang ada di Bali adalah Seni Tari dimana Seni Tari merupakan perwujudan seni yang menggunakan tubuh sebagai media ungkapnya.

Sebagai bentuk pelestarian budaya khususnya Seni Tari, banyak tumbuh lembaga- lembaga pendidikan Seni Tari baik formal, informal, maupun non formal yang tentu saja berdampak positif sebagai wujud dukungan masyarakat terhadap eksistensi Seni Tari Bali. Belajar menari Bali sebaiknya diperkenalkan sejak usia anakanak, sehingga muncul minat dan bakat yang ada dalam diri anak. Mengajarkan Tari Bali adalah tugas yang cukup berat melihat kondisi teknologi dan modernisasi yang terjadi dewasa ini akan mempengaruhi kebiasaan anak terhadap ketergantungan gadget dan tontonan modern yang ditayangkan di televisi. Untuk itu perlu dipahami bagaimana cara agar anak memiliki minat untuk belajar menari tradisi.

Dalam menari Bali diperlukan teknik tari yang kuat dan bagus sebagai pondasi bentuk tari selanjutnya. Teknik Tari adalah metode atau cara belajar menari dari dasar sebelum memulai belajar jenis atau bentuk tarian Bali. Teknik tari menjadi sangat penting sebagai pembentukan porposional tubuh penari agar memiliki lekuk dan dasar yang bagus dalam menari Bali. Belajar teknik tari di jaman dahulu tentunya lebih berat daripada jaman sekarang, hal ini dituturkan oleh para penari- penari dan guru tari yang tergolong ada di jaman lampau yaitu tahun 1960 an yang mana dalam belajar menari tentunya lebih menekankan pada teknik agem dan tandang yang baik. Metode pengajaran yang cenderung lebih kuat dalam pelatihan fisik membentuk tubuh 
penari lebih fleksibel dan lues, tekek. Bukan hanya hafalan bentuk gerak, tapi lebih menekankan pada teknik- teknik gerak tari yang secara terus menerus dilatih, sehingga tercipta bentuk atau lekukan- lekukan tubuh penari yang bagus dan good looking.

Perkembangan belajar menari dewasa ini tentunya mengikuti karakter dan pola pendidikan jaman sekarang, dimana lebih memperhatikan kondisi anak didik yang tentunya tidak bisa dipaksakan secara fisik. Dalam belajar teknik tari cenderung lebih membosankan daripada belajar sebuah bentuk tarian dengan secara langsung mendengar iringannya. Ketika belajar teknik tentu saja lebih lama dan geraknya berulangulang dilakukan sampai benar- benar ada pada gerak yang tepat.

Salah satu konsep kehinduan yang relevan dengan Teknik Tari Bali adalah konsep Tri Angga, dimana konsep ini merupakan konsep yang ada dalam pembagian tubuh manusia dengan istilah utamaning angga, madya angga, dan nista angga. Ketika konsep ini masuk di dalam Teknik Tari Bali, maka dapat dipahami bahwa konsep ini mampu memberikan pemahaman yang lebih terhadap pembagian tubuh saat mempelajari perbendaharaan gerak yang ada dalam teknik tari Bali. Pembagian tubuh ini mampu memudahkan pembelajaran dengan mengklasifikasikan gerak- gerak sesuai dengan pembagian tubuh (angga) penari. Sebelumnya konsep ini tidak diperkenalkan dalam belajar Teknik Tari, namun dirasa sangat penting dipahami konsep- konsep kehinduan yang terdapat dalam Teknik tari Bali, konsep dan relevansinya untuk diimplementasikan dalam pembelajaran Teknik Tari/Dasar Tari Bali.

\section{METODOLOGI}

Beberapa teori yang relevan digunakan dalam pembahasan ini adalah Teori Estetika danTeori berasal dari kata "aesthesis" yang berarti persepsi, pengalaman, perasaan, pemandangan. Kata ini untuk pertama kali digunakan oleh Baumgarten untuk menunjukkan cabang filsafat yang berkaitan dengan seni dan keindahan. (Hartoko dalam Mas Laksmi, 2014:24). Dalam hal ini, bahwa keindahan berhubungan erat dengan lidah dan selera perasaan. Kajian estetika dirumuskan Louis O. Kattsoff (dalam Triguna, 2013:XIV), yaitu estetika merupakan suatu teori yang meliputi (1) penyelidikan mengenai yang indah dan (2) prinsip - prinsip yang mendasari seni. Akan tetapi, ini berarti tidak mempersoalkan senimannya. Dengan demikian, kiranya dalam hal ini perlu disimak satu segi teori estetik yang lain, yaitu (3) pengalaman yang bertalian dengan seni atau perenungan atas seni. Singkatnya, kajian estetika senantiasa berhubungan dengan seni. Dengan demikian kesenian dapat dikatakan merupakan salah satu unsur yang mengandung rasa keindahan atau estetika.

Adapun estetika yang dilihat dari pandangan Agama Hindu merupakan pandangan mengenai rasa keindahan ( Lango ) yang diikat oleh nilai-nilai Agama Hindu yang didasarkan atas ajaran-ajaran kitab suci Weda. Ada beberapa konsep yang kiranya menjadi landasan penting dari Estetika Hindu. Konsep-konsep yang dimaksud antara lain: konsep kesucian, konsep kebenaran, dan konsep keseimbangan (Dibya, 2003:96). Karya seni bisa dipandang sebagai sabda, karena diciptakan berdasarkan tujuan tertentu dengan maksud menyampaikan sesuatu berupa lambang atau simbol. Di negara India, Tuhan dalam wujudnya sebagai Siwa Nataraja dikatakan sebagai pencipta musik dan tari segaligus pencipta seni yang Maha Agung. Konsep kesucian (shiwam), mencangkup nilai-nilai ketuhanan yang juga mencangkup yadnya dan taksu. Hal ini memiliki pandangan estetik yang diikat oleh 
nilai-nilai spiritual ketuhanan sesuai dengan ajaran agama Hindu, konsep kebenaran (satyam) mencangkup nilai kejujuran,ketulusan, dan kesungguhan, sesuai dengan ajaran agama Hindu yadnya yang dilakukan oleh masyarakat Hindu seyogiyanya dilaksanakan dengan penuh kejujuran hati, rasa tulus, dan niat yang sungguh-sungguh. Konsep keseimbangan (sundharam), mencangkup persamaan dan perbedaan dalam beberapa dimensi, identik dengan istilah Rwa Bhineda, sekala-niskala adalahdua unsur yang selalu ada dan saling mempengaruhi.

Estetika Hindu menjelaskan cara pandang mengenai rasa (lango) yang diikat oleh nilai-nilai Agama Hindu yang didasarkan atas ajaran kitab suci Weda. Konsep-konsep yang melandasi adalah konsep Kesucian (Shiwam) yaitu nilai ketuhanan yang mencakup taksu dan yadnya. Pandangan masyarakat di Bali memiliki pandangan estetik yang diikat oleh nilai spiritual ketuhanan sesuai dengan ajaran Agama Hindu. Kebenaran (Satyam) mencakup nilai kejujuran, ketulusan, dan kesungguhan. Yadnya atau persembahan seyogyanya dilaksanakan dengan nilai tersebut, karena atas dasar inilah Yadnya tersebut dapat diterima oleh Tuhan. Nilai kebenaran inilah yang diharapan umat Hindu dalam kehidupan agar tidak merusak kualitas hidup dan jati diri. Keseimbangan (Sundharam) dalam kesenian di Bali ada beberapa dimensi refleksi keseimbangan, yaitu dimensi dua dan dimensi tiga. Refleksi estetis dalam konsep dimensi dua menghasilkan bentuk simetris sekaligus asimetris, jalinan yang harmonis dan disharmonis yang disebut Rwa Bhineda. Refleksi estetis dalam konsep dimensi tiga terkait dengan konsep kosmologi Hindu yang membagi dunia ini menjadi tiga bagian, yaitu dunia bawah (Bhur Loka), alamnya para Bhutakala, Dunia Tengah (Bwah Loka), alamya manusia dan isi alam semesta, dan Dunia atas (Shwah Loka) alamnya para dewata.

Ketiga konsep ini menjadi landasan berkarya bagi seniman dalam mewujudkan sebuah karya seni yang memiliki nilai filosofi Agama Hindu yang tinggi. Dalam Seni Tari khususnya konsep tersebut dapat digunakan dalam mengupas permasalahan dalam segi bentuk dan makna dari konsep Tri Angga. Teori berikutnya adalah Teori Simbol, dimana menurut Triguna (2007:7) mengatakan bahwa simbol adalah suatu hal atau keadaan yang merupakan pengantaraan pemahaman terhadap obyek. Manifestasi serta karakteristiknya, simbol tidak terbatas pada isyarat fisik (artefak) saja, tetapi dapat berupa kata - kata dan tindakan. Masih dalam pengertian simbol, seorang psikolog yang bernama Carl Jung yang dikutip Triguna (2000:32), menjelaskan bahwa simbol adalah formulasi dari ekspresi yang paling baik akan sesuatu yang relatif tidak dikenal, namun hal ini diketahui ada atau diharapkan ada. Menurut Jung fungsi simbol adalah untuk mengungkapkan hal yang tidak terkatakan dalam cara yang tidak teratasi. Jadi, berdasarkan pendapat di atas dapat disimpulkan teori simbol merupakan teori yang difungsikan sebagai ekspresi dan koseptual dalam mengungkapkan sesuatu. Dalam Tekni Tari Bali terdapat banyak simbol- simbol dari gerak, level, yang dapat menentukan karakteristik atau jenis Tarinya.

\section{PEMBAHASAN}

\subsection{Teknik Tari Bali}

Tari adalah gerak dengan menggunakan tubuh sebagai media ungkap keindahan rasa dengan aspek - aspek dalam Tari adalah bentuk, gerak, tubuh, irama, jiwa. Unsur utama Tari adalah gerak, tenaga atau energi yang mencakup ruang dan waktu. Gerak dapat dibagi menjadi dua jenis, yaitu gerak murni yaitu gerak yang disusun untuk mendapatkan keindahan tanpa ada arti khusus. Sedangkan gerak 
maknawi merupakan gerak yang mengandung arti atau maksud tertentu dan telah distilisasi menjadi gerak wantah. Dalam Tari Bali terdapat beberapa istilah yang sering digunakan, yaitu Wiraga, Wirama, dan Wirasa, dimana hal ini sangat penting sebagai pedoman dan tata cara dalam mempelajari Tari Bali.

Teknik tari Bali merupakan Cara atau metode dalam belajar Tari Bali sebagai dasar atau pondasi dalam pembentukan tari yang baik. Dalam belajar menari tentu saja diharuskan memiliki dasar yang kuat dan benar, agar selanjutnya dapat menarikan sebuah bentuk tarian yang baik dengan pakem tari yang jelas. Teknik Tari Bali dibagi menjadi dua jenis, yaitu Teknik Tari Putra dan Teknik Tari Putri, sesuai dengan karakteristik Tari Tradisi Bali. dalam Teknik Tari Putra dapat dijabarkan lagi dalam dua jenis, yaitu Putra Keras dan putra Halus. Sedangkan dalam Teknik Tari Putri terdapat Teknik Putri keras dan Putri halus. Terdapat banyak istilah- istilah yang digunakan dalam tari Bali, terutama dalam menggambarkan perbendaharaan geraknya. Beberapa diantaranya yang sering dan harus diketahui dalam belajar Tari Bali adalah:

- Agem, merupakan sikap pokok dalam Tari Bali

- Tandang, merupakan Gaya, gerak gerik dalam Tari Bali sesuai dengan watak dari tokoh yang diperankan. Tandang juga merupakan gerakan perpindahan dari satu gerakan pokok ke gerakan yang lainnya. Tandang dapat dibagi menjadi dua, yaitu Abah dan Tangkis.

- Tangkep, merupakan ekspresi yang timbul melalui cahaya muka atau mimik. Istilah- istilah di atas merupakan dasar yang utama dalam mempelajari Tari Bali yang dalam prakteknya mempunyai cara atau teknik yang memiliki pakem atau aturan khusus dalam Tari Bali.

Selain teknik gerak, juga dipelajari mengenai ekspresi (Tetuek) dalam tari Bali yang memiliki teknik tertentu dan pakem yang telah diatur. Ekspresi atau mimik/tetuek termasuk dalam teknik tari Bali karena terdapat beberapa cara dan aturan dalam belajar Tari Bali. Tidak hanya gerak yang unik, tari bali juga memiliki ekspresi yang identik dan memiliki ciri khas, seperti nelik, encah cerengu, dan lain sebagainya yang telah memiliki aturan atau pakem.

\subsection{Konsep Tri Angga Dalam Belajar Teknik Tari Bali}

Konsep Tri Angga atau juga disebut Tri Loka merupakan sebuah konsep ruang turunan dari konsep Tri Hita Karana yang dimiliki masyarakat Bali sebagai pedoman keselarasan hidup yang harmonis antara manusia dan alam. Konsep Tri Angga umumnya digunakan dalam arsitektur Bali sebagai struktur pembagian Loka 'tempat bangunan' dalam harmonisasi dengan alam makrokosmos. Tri Angga jika dianalisa mengenai asal katanya yaitu Tri berarti Tiga, dan Angga berarti badan. Konsep ini dapat diproyeksikan dalam Teknik Tari Bali sebagai pembagian tubuh manusia sebagai media gerak tari yang saling terhubung untuk memperoleh sebuah wujud tari yang indah.

Dalam Seni Tari konsep mempengaruhi bentuk, fungsi hingga makna tarian. Beberapa Konsep yang terdapat dalam suatu bentuk tari Bali diantaranya konsep Estetika Hindu, konsep Rwa Bhineda, dan konsep lainnya. Spesifikasi konsep Tri Angga sangat terkait dengan Teknik Tari Bali yang belum banyak dikupas dalam kajian- kajian teoritis Tari Bali. Konsep Tri Angga merupakan sebuah konsep kehinduan yang biasanya dipergunakan dalam arsitektur bangunan Bali yang membagi bagian perbagian sebuah wilayah, seperti dalam wilayah tempat suci (Pura) terbagi atas tiga wilayah (Tri 
Mandala) yaitu Utamaning mandala, madyaning mandala, dan nistaning mandala.

Konsep arsitektur Bali ini juga dapat berkaitan dengan konsep Bhuana Agung dan Bhuana Alit, yaitu adanya garis vertikal dalam wilayah Bhuana Agung, seperti konsep Bhur, Bwah, swah (atas, tengah dan bawah ). Konsep pada Bhuana Alit atau pada manusia yang juga dapat terbagi menjadi tiga bagian (Tri Angga) yaitu Utamaning Angga, Madya Angga, dan Nista Angga. Dalam bukunya Estetika Hindu dan Pembangunan Bali (Dibia, 2003:105), Konsep Tri Angga merupakan konsep yang didefinisikan sebagai sebuah pembagian ruang secara vertikal menjadi tiga bagian/ wilayah tubuh manusia yaitu Kepala sebagai utama angga (yang paling disucikan), badan atau torso (dari dada sampai pinggul) sebagai madya angga bagian yang disucikan dalam level kedua, dan bagian kaki sebagai nista angga (dianggap paling tidak suci). Konsep Tri Angga memudahkan dalam pembelajaran Teknik Tari Bali karena adanya pemahaman mengenai pakempakem gerak tari yang telah diatur dan memiliki nilai yang sangat tinggi. Salah satu contoh adalah gerakan kaki dalam Tari Bali yang masih asli dan tradisi, tidak akan mengangkat kaki melewati daerah (nista) yaitu sebagai batas atasnya adalah pinggang (gerakan kaki gandang- gandang, nengkleng gelatik nut papah, malpal, dll ). Hal ini merupakan pemahaman yang seharusnya dipertahankan dengan dasar konsep kehinduan Tri Angga.

Beberapa contoh gerakan Teknik Tari Bali dengan pembagian Tri Angga sebagai metode mempermudah dalam pembelajaran adalah sebagai berikut :

1. Utamaning Angga, yaitu bagian utama dalam tubuh yang dalam Estetika Hindu dikaitkan dengan bagian yang paling disucikan adalah bagian kepala. Dalam belajar Teknik Tari Bali ada berbagai jenis gerak yang bersumber pada bagian kepala, diantaranya Ngotag, Ngontel, Kipekan, Ulu Wangsul, Seledet, dan gerakan yang termasuk Tangkep atau Mimik.

2. Madyaning Angga, merupakan bagian kedua dalam pembagian Tubuh diantaranya bagian Torso atau badan, dari bahu hingga pinggul. Dalam bagian ini terdapat banyak perbendaharaan gerak yang ada, beberapa contohnya adalah gerakan Ngejat Pala, Ngeseh, Ngelo, Nyeleog, dan lainnya.

3. Nistaning Angga, merupakan bagian terakhir dari pembagian ini yang terdapat pada bagian bawah pinggil dan kaki. Dalam Tari Bali terdapat beberapa perbendaharaan gerak yang paling utama yang menekankan pada kaki sebagai pondasi atau dasar berdiri dmenari. Bagian ini sangatlah penting, karena untuk mendapatkan gerak tari yang bagus haruslah memiliki pondasi yang kuat, dimana kaki sebagai pijakan tubuh dalam menari. Gerakan- gerakan yang paling mendasar diantaranya, gerakan Malpal, Ngegol, Nayog, Gandang- Gandang, Nengkleng, dan lain sebagainya. Hal yang paling mendasar dalam menjaga keseimbangan tubuh dalam menari adalah posisi kaki Tapak Sirang Pada yang dalam prakteknya memiliki pakem atau aturan yang tidak dapat dirubah.

Dalam Tari Bali, selain gerak yang ritmis dan dinamis, Tari Bali memiliki pakem gerak Mata yang terkenal indah dan tidak mudah dalam melakukannya. Gerakan mata yang disebut seledet juga memiliki cara atau teknik dalam pembelajarannya. Dari gerakan mata ini akan terpancar rasa dan pesan yang ingin disampaikan dengan adanya penjiwaan yang dalam dan tulus dari penarinya. Gerakan mata atau seledet ini terdapat pula beberapa perbendaharaan geraknya diantaranya seledet capung, 
ngelangkar gunung, dan lainnya. Istilahistilah ini biasanya diperoleh atau terinspirasi dari alam dan lingkungan.

Gerakan- gerakan dalam Teknik Tari Bali dapat diklasifikasikan dalam dua jenis, yaitu gerakan maknawi dan gerakan murni. Gerakan maknawi merupakan gerakan yang memiliki arti atau makna gerak yang sudah diperindah, contohnya gerakan ulap-ulap yang memiliki arti melihat sesuatu yang ada di depan penari. Gerakan ngepik berarti memetik atau mengambil sesuatu seperti bunga. Gerakan nuding berarti menunjuk seseorang. Sedangkan gerak murni seperti gerakan jeriring, yaitu gerakan jari tangan yang digetarkan memiliki nilai keindahan. Terdapat banyak perbendaharaan gerak dalam tari Bali yang dapat dijabarkan.

\section{PENUTUP}

Belajar Tari Bali merupakan hal yang dilakukan mengenai rasa dan keindahan, sehingga perlu ketekunan dan tekad yang bulat dalam mendalaminya. Teknik tari Bali sangat terkait dengan konsep kehinduan yang dapat memberikan warna tersendiri, sehingga menjadi daya tarik untuk mempelajarinya. Pakem- pakem tradisi yang terdapat dalam Tari Bali menjadikan Tari Bali sebuah seni yang unik dan keberadaannya masih lestari hingga sekarang. Konsep Tri Angga terdapat dalam Teknik Tari Bali sebagai konsep seni dan kehinduan yang saling berkaitan. Konsep ini mempermudah dalam mempelajari Teknik Tari Bali dengan mengklasifikasikan perbendaharaan gerak tari yang ada sesuai dengan konsep Tri Angga yang direfleksikan dalam struktur tubuh penari sesuai dengan pembagian Tri Loka sebagai turunan konsep Tri Hita Karana dalam Agama Hindu. Selain Gerak yang telah dijabarkan diatas, Tari Bali Terkenal dengan gerak mata yang unik, teknik gerakan mata yang umumnya disebut seledet merupakan teknik yang tidak hanya dipelajari dengan metode baku atau pakem yang ada, tetapi lebih pada penjiwaan yang nantinya memberikan cahaya dan memancarkan taksu atau daya tarik geraknya.

\section{DAFTAR PUSTAKA}

Bandem, I Made.1982. Ensiklopedia Tari Bali. Denpasar : Akademi Seni Tari Indonesia

Bandem, I Made. 2004. Kaja dan Kelod Tarian Bali dalam Transisi. Yogyakarta: Institut Seni Indonesia Yogyakarta.

Departemen Pendidikan dan Kebudayaan. 1990. "Kamus Besar Bahasa Indonesia". Jakarta: Balai Pustaka.

Dibia, I Wayan. 2013. Pupasari Seni Tari Bali. Denpasar: Institut Seni Indonesia Denpasar.

Djelantik, A.A. 1990. Pengantar Dasar Umum Estetika. Denpasar : Sekolah Tinggi Seni Indonesia.

Djelantik, A.A. 1999. Estetika Sebuah Pengantar Seni Pertunjukan. Bandung: Masyarakat Seni Pertunjukan Bandung. 
Mantra, Ida Bagus Made. 1993. Bali Masalah Sosial dan Modernisasi. Denpasar: Upadha Sastra.

Maleong, Lexy J. 1990. Metodologi Penelitian Kualitatif. Bandung: Remaja Rosdakarya.

Milles, Matthew B,A, and Michael Huberman. 1992. Analisis Data Kualitatif. Jakarta: Universitas Indonesia.

Soedarsono SP. 2006. Trilogi Seni Pertunjukan. Yogyakarta: BP ISI Yogyakarta

Suamba, Ida Bagus Putu. 2003. "Siwa Nataraja: Simbol Filsafat dan Signifikansinya dalam Kesenian Bali.” Dalam Estetika Hindu dan Pembangunan Bali. (hlm.4-6)

Suasthi Widjaja Bandem, N.L.N. 2012. Dharma Pagambuhan. Denpasar: STIKOM Bali

Yudabakti, I Made dan I Wayan Watra.2007. Filsafat Seni Sakral. Surabaya : Paramita Surabaya

Yudha Triguna, IBG. 2000. Teori Tentang Simbol. Widya Dharma UNHI : Denpasar Timur 